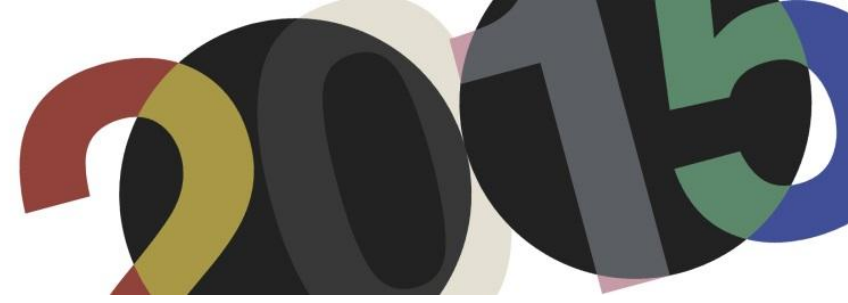

DOI: http://dx.doi.org/10.4995/LC2015.2015.985

\title{
Crónica de un desencuentro: Le Corbusier en las Américas
}

\author{
A. Lapunzina \\ Illinois School of Architecture, University of Illinois at Urbana-Champaign
}

\begin{abstract}
Resumen: La relación de Le Corbusier con el continente americano abarca virtualmente toda su vida activa. Plasmada en una veintena de viajes trasatlánticos y en un conjunto heterogéneo de propuestas, proyectos y obras, esta relación estuvo marcada por frecuentes malentendidos y desencuentros que condicionaron la concreción de algunos de sus proyectos. No obstante, el valor de su obra americana, representada por dos obras extraordinarias -la Casa Curutchet en Argentina y el Carpenter Center en Estados Unidos-y por una serie de proyectos notables que no llegaron a materializarse, merece un tratamiento específico. Este artículo está dedicado a presentar una síntesis de la relación y recíproco desencuentro entre Le Corbusier y el continente americano.
\end{abstract}

\begin{abstract}
The relationship between Le Corbusier and the American continent virtually encompasses his entire professional life. Embodied by about twenty transatlantic trips and a series of heterogeneous projects and buildings, this relationship was marked by frequent misunderstandings that conditioned the materialization of some of his projects. However, the significance of Le Corbusier's work for the Americas, represented by two extraordinary buildings -the Curutchet House in Argentina and the Carpenter Center in the United States- and by a series of noteworthy projects that remained unbuilt, deserves special consideration. This article is dedicated to present an outline of the relationship and reciprocal misunderstanding between Le Corbusier and the American continent.
\end{abstract}

Palabras clave: Américas; Planes urbanos; Casa Curutchet; Carpenter Center; Viajes y Proyectos. Keywords: Americas; Urban Plans; Curutchet House; Carpenter Center; Travels and Projects.

\section{Introducción}

A lo largo de su extendida trayectoria profesional Le Corbusier mantuvo una intensa relación con las Américas. Compleja y ambigua, esta relación fue generada y nutrida por él mismo y por numerosos interlocutores con los que el arquitecto trabó relación, primero en París y más tarde a través de sus viajes al continente americano. Entre sus primeros interlocutores destacaron miembros de las élites sociales y culturales americanas pero más tarde, a medida que su fama y prestigio internacional crecían, se fueron sumando personalidades de otros ámbitos - políticos, intelectuales, artistas, profesionales - y jóvenes colegas, algunos de los cuales colaboraron con él en diversos proyectos o instancias de su actividad profesional. Sustentada en dichas relaciones personales y en una veintena de viajes trasatlánticos, la relación entre Le Corbusier y las Américas fue ciertamente rica y quedó plasmada en un conjunto heterogéneo de proyectos, desde pequeños encargos privados hasta ambiciosos planes urbanos. ${ }^{1}$ Solo dos llegaron a concretarse: la Casa Curutchet en La Plata, Argentina (1949-1952) y el Carpenter Center for the Visual Arts en Harvard University, Cambridge, Estados Unidos (1959-1963). El resto, encargos directos o propuestas desarrolladas por iniciativa propia, no llegaron a materializarse por diversos

\footnotetext{
${ }^{1}$ La bibliografía dedicada a la relación de Le Corbusier con el continente americano es abundante y variada, desde obras monográficas, hasta artículos y tesis doctorales. Desde un punto de vista metodológico hubiera sido necesario referirse a las fuentes bibliográficas a medida que transcurre el texto, pero esto excede la extensión fijada para el mismo. Por lo tanto he optado por proveer en la bibliografía incluida al final del artículo una lista (incompleta) de publicaciones dedicadas a la relación, viajes, proyectos y obras de Le Corbusier en el continente americano.
} 
motivos. Este trabajo plantea que entre las razones que limitaron la concreción de algunas obras, una de las principales fue el desencuentro entre Le Corbusier y las Américas, consecuencia directa de frecuentes conflictos y malentendidos que surgieron en la gestación y/o desarrollo de los proyectos. ${ }^{2}$ Las razones de dichos malentendidos tuvieron origen en su personalidad y en su peculiar y poco objetiva interpretación de la realidad americana, así como también en la pugna entre las expectativas en torno al rol que él creyó tener en cada contexto específico y el que sus interlocutores americanos efectivamente le asignaron, o creyeron asignarle. Las excepciones de la Casa Curutchet y el Carpenter Center constituyen casos aislados en los que las situaciones conflictivas fueron superadas en parte gracias a la gestión de terceros actores que llevaron a cabo los respectivos procesos de concreción de estas dos obras extraordinarias, legado americano de la arquitectura universal y atemporal de Le Corbusier.

\section{Breve Cronología de los viajes, obras y proyectos de Le Corbusier en las Américas}

Al igual que a sus colegas europeos, el continente americano atrajo el interés de Le Corbusier desde el principio de su carrera. El crecimiento vertiginoso de los Estados Unidos, los procesos de mecanización e industrialización puestos allí en práctica, y la extensión de un territorio con ciudades jóvenes y en franco desarrollo aparecían como un terreno fértil para los pioneros de la arquitectura y el urbanismo modernos. Naturalmente, Le Corbusier no fue ajeno a esta tendencia y con frecuencia se refería al continente americano para ilustrar sus ideas y postulados. A mediados de los años veinte, su amigo Blaise Cendrars le presentó en París al poeta y escritor brasileño Paulo da Silva Prado, miembro de una familia influyente de São Paulo; ambos instigaban a Le Corbusier a emprender un viaje a Brasil donde la perspectiva de verse involucrado en el proyecto de Planaltina (germen de lo que años más tarde sería Brasilia) eran más que un aliciente para el joven arquitecto cuyas ideas, postulados y obras construidas ya trascendían las fronteras de Europa. También en París y por aquellos mismos años, Le Corbusier entabló relación con miembros de las élites pudientes de las Américas que residían o visitaban frecuentemente la capital francesa. Con el estímulo de estos contactos, llevar sus ideas al continente americano atrajo a Le Corbusier desde el primer momento, pero aún pasarían unos años para que se concretaran sus primeros viajes trasatlánticos.

Le Corbusier viajó a las Américas numerosas veces - en barco, avión y dirigible - ya sea para dar conferencias o en relación a proyectos de arquitectura y/o urbanismo. Siempre ávido de propagar sus ideas y obtener encargos, aprovechaba estos viajes para establecer contactos que pudieran abrirle las puertas a oportunidades y proyectos interesantes. El primer viaje fue en 1929 para dar un ciclo de conferencias en Buenos Aires; más tarde se sumaron al periplo sudamericano conferencias en Montevideo, São Paulo y Río de Janeiro. Seis años más tarde, en 1935, realizó el primer viaje a Estados Unidos, también para ofrecer conferencias en ciudades de la costa este y del medio-oeste. Invitado por el gobierno brasileño, en 1936 regresó a Río de Janeiro, nuevamente para dictar conferencias y como consultor de dos proyectos públicos de envergadura. Apenas terminada la segunda

\footnotetext{
${ }^{2}$ La figura del "malentendido" es recurrente en la bibliografía sobre la relación de Le Corbusier con el continente americano. William Curtis observó que "Le Corbusier y América [NdA: se refiere a los Estados Unidos] no consiguieron establecer un contacto duradero por haber malinterpretado señales a un lado y al otro." Curtis, William J. R. Le Corbusier Ideas and Forms; New York: Rizzoli, 1987 (126); por su parte Fernando Pérez Oyarzun notó que "la carrera de Le Corbusier en América del Sur fue un catálogo de fracasos y malentendidos." Pérez Oyarzún, Fernando. Le Corbusier in South America: Reinventing the South American city. Publicado en Mostafavi, Mohsen (ed.) Le Corbusier and the Architecture of Reinvention; London: Architectural Association, 2003 (140-153). Estos son sólo dos ejemplos entre muchos, incluyendo artículos que llevan "el malentendido" como tema principal.
} 
guerra mundial, Le Corbusier hizo numerosas idas-y-vueltas a Estados Unidos en relación al proyecto de las Naciones Unidas, y entre 1947 y 1951 viajó cinco veces a Colombia, primero para dar conferencias y luego en relación al Plan de Bogotá que le fuera encomendado. En 1959 y 1960 viajó a Estados Unidos en conexión con el encargo de proyectar el Carpenter Center, y en 1961 regresó por última vez al país del norte para recibir prestigiosas distinciones, entre ellas la Gold Medal del American Institute of Architects. El último viaje al continente americano fue a fines de 1962 para visitar en Brasilia el solar de la Embajada de Francia que le había sido encomendada anteriormente.

La documentación existente en los archivos de la Fondation Le Corbusier revela la existencia de una docena de proyectos de arquitectura y/o urbanismo en las Américas. A pesar que desde mediados de los años veinte habían existido tímidos intentos de obtener sus servicios desde distintos puntos del continente, el primer encargo concreto fue en 1928: una casa en Buenos Aires para la joven escritora e intelectual argentina Victoria Ocampo. A fines de 1929, durante su periplo por Sudamérica, obtuvo tres encargos: una casa de vacaciones en Chile para el diplomático chileno Matías Errázuriz, un pabellón residencial para Julián Martínez en Buenos Aires, y una biblioteca privada en los jardines de la casa de Paulo Prado en São Paulo. A principios de los años treinta hizo esquemáticos bocetos para un atelier de pintura en Santiago de Chile a pedido del pintor chileno Roberto Dávila. En 1935, durante su largo viaje por los Estados Unidos la cosecha de encargos no fue tan rica como lo había sido en el sur seis años antes; no obtuvo ningún encargo concreto pero aun así hizo un proyecto esquemático para la residencia del Presidente del Olivet College, en Michigan. En aquellos periplos por el sur y el norte del continente produjo, generalmente como parte de sus conferencias sobre urbanismo, provocadoras propuestas urbanas para Buenos Aires, Montevideo, São Paulo (1929), Río de Janeiro (1929 y 1936) y Manhattan (1935) que -por su importancia teórico-conceptual—deben ser consideradas como gérmenes de ideas urbanísticas.

En su segunda estadía en Brasil, en 1936, participó como consultor en los proyectos de la Ciudad Universitaria de Río de Janeiro y del nuevo edifico para el Ministerio de Educación y Salud que estaban siendo proyectados por dos equipos de jóvenes arquitectos brasileños dirigidos por Lucio Costa. Hacia fines de los años treinta el inminente estallido de la segunda guerra mundial virtualmente paralizó la actividad profesional en Europa. En este contexto, fiel a su incansable afán de concebir propuestas que pudieran generar algún tipo de actividad, Le Corbusier aprovechó circunstancias fortuitas para producir un no-solicitado pero ambicioso Plan Regulador para Buenos Aires (1938-1939). El fin de la guerra inauguró uno de los períodos de mayor intensidad no sólo en la obra de Le Corbusier en general sino también en su relación con el continente americano. Representando a Francia, Le Corbusier integró el equipo de expertos internacionales encargado de proyectar la sede central de las Naciones Unidas. A fines de los años cuarenta, el gobierno de Colombia le encargó un Plan Piloto para Bogotá, proyecto realizado en colaboración con Josep Lluis Sert y Paul Lester Wiener. Coincidiendo en el tiempo, la publicación del Plan Regulador para Buenos Aires de 1938-39 reavivó sus expectativas en la capital argentina, y paralelamente, en 1948 recibió y aceptó el encargo directo de proyectar una vivienda y consultorio médico para el Dr. Pedro Curutchet en La Plata (Argentina) que fue su primera obra construida en el continente americano. Este intenso lustro de "actividad americana" (1946-1951) culminó con el encargo de proyectar en Caracas un Monumento Funerario para Carlos Delgado-Chalbaud, presidente venezolano asesinado en noviembre de 1950 en confusas circunstancias.

Los últimos dos proyectos realizados por Le Corbusier para el continente americano son el Carpenter Center for the Visual Arts en Harvard University (1959-1963), encargo gestionado por Josep Lluis Sert, y la Embajada de Francia (1962-1965) en la entonces recientemente inaugurada nueva capital de Brasil. El primero de ellos se convirtió en el segundo y último edificio construido, mientras que el proyecto para la Embajada de Francia, que 
quedó pendiente a la muerte del arquitecto, cierra la lista de propuestas, proyectos y obras de Le Corbusier en las Américas.

\section{Un mutuo interés; un persistente desencuentro}

El interés de Le Corbusier por las Américas y el de los americanos por sus ideas fue recíproco; por un lado, el corpus teórico de Le Corbusier atrajo desde muy temprano a las élites intelectuales y a las generaciones emergentes de arquitectos y urbanistas americanos, y por el lado de Le Corbusier, el continente americano se presentaba como un territorio fértil para concretar sus ideas. La previsible convergencia de ambos era ciertamente promisoria, pero aunque se buscaron y convergieron una y otra vez, la relación entre Le Corbusier y las Américas estuvo signada por un persistente desencuentro. Una de las razones que explican este desencuentro fue la personalidad de Le Corbusier y su constante puesta en escena de una ambigua estrategia de relación que Margdes Bacon caracterizó como orientada a provocar en forma simultánea "antipatía y atracción;"3 otra de las razones puede atribuirse a su crónico rechazo a aceptar realidades que no se correspondían con la idea que él mismo se había forjado sobre esas mismas situaciones. Pero tampoco debe ignorarse la respuesta o actitud de sus interlocutores americanos que a menudo recurrieron al talento, prestigio y autoridad intelectual de Le Corbusier como aval de sus propios intereses y proyectos pero a veces fueron recelosos de su participación directa en procesos que pudieran desembocar en obras concretas. Sea por una razón u otras, lo cierto es que salvo las dos excepciones ya mencionadas, uno tras otro los proyectos de Le Corbusier para las Américas no llegaron a consumarse.

Aunque estuvo y/o realizó proyectos para otros países (Chile, Uruguay, Venezuela), la relación profesional de Le Corbusier con las Américas estuvo limitada a cuatro países: Argentina, Brasil, Colombia y Estados Unidos. Con diferentes matices -sobre todo entre los países de América del Sur y los Estados Unidos — afrontó su relación de forma semejante con una mezcla de interés personal y profesional y un cierto paternalismo franco-europeo. Objetivamente, la relación con los Estados Unidos fue la más conflictiva, con recíprocas resistencias a aceptarse mutuamente que quedaron plasmadas en una multitud de situaciones entre las que destacan ácidos intercambios al final de su tour de conferencias en 1935 y su controvertida participación en el proyecto de las Naciones Unidas. Indudablemente, ni en los Estados Unidos estaban dispuestos a "negociar" su propia visión de la modernidad, demostrado progreso, proyección cultural y rol de liderazgo que, basados en su creciente poderío económico y político, aspiraban a consolidar, ni Le Corbusier dispuesto a aceptarlo pasivamente sin exponer -e intentar imponer - sus fuertes convicciones y postulados. Por su lado, en Sudamérica, las élites eran más propensas a mirar hacia Europa y por ende más proclives a aceptar el liderazgo de Le Corbusier como portavoz de las ideas modernas. No obstante, la relación de Le Corbusier con los países del sur tampoco fue fácil y tuvo desenlaces mayormente negativos tanto en Argentina como en Colombia. Aunque lejos de perfecta e ideal, quizás tuvo mejor relación con Brasil, posiblemente gracias a su amistad con Lucio Costa y Oscar Niemeyer (mas allá de diferencias notables con ambos), relación que quedó plasmada con el encargo y construcción de la Maison du Brésil en la Cité Universitaire de París.

Sin embargo, a pesar de los matices y de ser plenamente consciente de las marcadas diferencias entre los Estados Unidos y Sudamérica, en su peculiar visión de las cosas Le Corbusier consideraba al continente y a su gente como una totalidad. Una nota interna del atelier es particularmente reveladora en este sentido: en 1955, enterado de la decisión de Brasil de poner en marcha el proceso de diseño de una nueva y moderna capital en el Planalto,

\footnotetext{
${ }^{3}$ Bacon, Margdes. Le Corbusier in America. Travels in the Land of the Timid; Cambridge (MA)-London: The MIT Press, 2001 (136).
} 
movilizó sus contactos para verse involucrado en la planificación de la nueva ciudad. Luego de muchas frustraciones, algunas muy recientes, su esperanza de construir algo importante en aquel continente fértil y pujante renacía. En una nota pidiendo a sus colaboradores Ducret y Wogenscky que prepararan materiales para el proyecto de la nueva capital de Brasil también advertía que "no hay que olvidar que he sido segado en: a) Río de Janeiro, Ministerio de Educación; b) Río de Janeiro, Ciudad Universitaria; c) Buenos Aires: Plan; d) New York: UN." Aquella nota reflejaba, en pocas palabras, su frustración con todo el continente, pero aun así no iba a dejar pasar la oportunidad de proyectar la nueva capital de Brasil; pero la nota también demostraba su particular interpretación de los hechos precedentes ya que, curiosamente, en ninguno de esos casos había sido contratado para hacerse cargo del proyecto.

Con el tiempo, su fascinación inicial con el continente americano fue cediendo paso a un sentimiento de frustración que, sin embargo, no impidió que volviera una y otra vez cuando un proyecto le entusiasmaba. En 1928, aun antes del primer viaje al continente americano, Victoria Ocampo le encargó por vía indirecta el proyecto de una casa en Buenos Aires. La historia es conocida: quizás por las semejanzas del programa y el terreno, Le Corbusier rescató su frustrado proyecto para la Villa Meyer (Neuilly-sur-Seine, 1925) y con muy ligeras modificaciones se lo envió a su cliente argentina. Curiosamente Victoria Ocampo había encargado un proyecto similar pero en otro solar al reconocido arquitecto argentino Alejandro Bustillo y fue este último el que decidió construir. Cuando tan solo un año más tarde Le Corbusier visitó Buenos Aires, la escritora -una de sus principales anfitrionas - lo recibió en esa flamante casa que había construido en desmedro de su proyecto. Sin embargo, elegante y perspicaz, Le Corbusier elogió la "casa moderna" y la determinación de Victoria Ocampo por construir una obra de esa naturaleza; había indudablemente percibido su posición social y poder económico, que aunados a esa determinación, podían ser llaves que abrieran puertas a interesantes emprendimientos. Muy pronto propuso a su anfitriona una variedad de iniciativas: un rascacielito cerca del Río de la Plata y un complejo de viviendas tipo Villa Savoye en el Tigre, pero ninguno de ellos prosperó.

La Casa Errázuriz en Zapallar (Chile, 1930) sufrió un destino similar. Errázuriz le había encargado el proyecto a Le Corbusier durante su estadía en Buenos Aires. Le Corbusier abordó el proyecto a principios de 1930 y lo envió a su cliente en abril de ese año. Sin embargo, a pesar de su satisfacción con el proyecto de Le Corbusier, Errázuriz decidió construir otro, proyectado por Carlos Landa, arquitecto mexicano establecido en Chile. Le Corbusier no llegó a enterarse y años más tarde seguía ignorando qué había pasado con su proyecto al mismo tiempo que veía con indignación como Antonin Raymond plagiaba su proyecto en Japón. ${ }^{5}$ Los otros proyectos para clientes americanos que Le Corbusier produjo en la primera mitad de los años treinta tampoco llegaron a materializarse. De todos ellos, el pabellón para Julián Martínez es el único que tuvo una base contractual sólida y al que Le Corbusier respondió con un proyecto acabado. Se ignoran las causas del frustrado desenlace del proyecto y es muy probable que sean debidas a cuestiones personales del cliente. De la biblioteca para Paulo Prado en São Paulo solo existen unos pocos dibujos que revelan las intenciones e ideas de Le Corbusier, pero este proyecto fue abortado mucho antes que el proceso de diseño concluyera. La Casa para el Presidente del Olivet College en Michigan fue el único encargo que Le Corbusier creyó haber obtenido en su periplo por los Estados Unidos en 1935. No fue un encargo firme, pero surgió como una oportunidad en conversaciones con Henry Russell Hitchcock y Joseph Brewer (Presidente del Olivet College) durante el breve pasaje de Le Corbusier por Michigan. Le Corbusier no dejó pasar la oportunidad y respondió de inmediato con dibujos

\footnotetext{
${ }^{4}$ Nota interna del atelier de Le Corbusier dirigida a Wogenscky y Ducret; Junio 6, 1955. Archivos FLC, D1-03 (356).

${ }^{5}$ Carta de Le Corbusier al hijo de Errázuriz; Febrero 27, 1948; Archivos FLC G2-10, (84).
} 
esquemáticos pero sin duda interesantes, pero a pesar del entusiasmo de Brewer por las ideas de Le Corbusier el encargo no se materializó.

Los episodios y malentendidos más resonantes y complejos tuvieron lugar entre 1936 y 1952 con los planes para Buenos Aires y Bogotá (tratados separadamente), y con la actuación de Le Corbusier en Brasil (1936) y en el proceso de diseño de las Naciones Unidas (1945-1948). Esa década y media estuvo profundamente marcada por el estallido de la segunda guerra mundial y ante la inminencia de la guerra y la consecuente falta de obras y encargos, Le Corbusier consideró la posibilidad de emigrar temporalmente a América del Sur; intentó tender algunos lazos con Chile, Argentina y Brasil pero además de hospitalidad, muy poco o nada se le ofreció en concreto, y esa posibilidad -aunque débil — se apagó rápidamente. Le Corbusier optó entonces por quedarse en Francia, pero quizás otra hubiera sido la historia si de alguno de aquellos países hubiera llegado un contrato firme para alguna obra importante.

En 1936, Le Corbusier aceptó dar un ciclo de conferencias en Río de Janeiro con la condición de que incluyera algún tipo de actividad profesional; eventualmente se llegó a un acuerdo involucrándolo como consultor en los proyectos de la Ciudad Universitaria de Río de Janeiro y del Ministerio de Educación y Salud en los que trabajaban equipos dirigidos por Lucio Costa. Oficialmente, su rol estaba limitado a comentar los proyectos en curso pero Le Corbusier aspiraba a tener un protagonismo mayor y pronto asumió un rol más importante. Intuyendo su importancia se interesó particularmente en el proyecto para el Ministerio. Luego de elogiar la labor del equipo dirigido por Costa, pasó a la ofensiva cuestionando el emplazamiento elegido y proponiendo otro que juzgaba más apropiado. La proposición no fue inocente: este respondía mejor a sus ideas para Río de Janeiro esbozadas en 1929 y aunque esquemáticos, sus dibujos pueden ser interpretados como un fragmento de aquella visionaria propuesta. Además, de esta forma los roles quedaban implícitamente trastocados y él asumía de facto la dirección de Costa y su equipo. Poco antes del fin de su estadía el cambio de sitio fue descartado, y en vez de dejar que el proyecto original de Costa y sus colaboradores siguiera su curso, invirtió el poco tiempo que disponía en esbozar rápidamente una adaptación al terreno original de su esquema para el sitio alternativo. Luego de la partida de Le Corbusier, Costa y su equipo retomaron el proceso de diseño incorporando algunos aspectos sugeridos en los últimos bocetos que Le Corbusier había presentado, pero el proyecto definitivo, que una vez construido se convirtió en ejemplo paradigmático de la arquitectura moderna, fue enteramente desarrollado por el equipo dirigido por Costa. Grande fue la sorpresa y la desilusión de estos últimos al advertir que Le Corbusier se adjudicaba la coautoría del edificio cuando su participación en el proyecto definitivo fue prácticamente inexistente. Por su parte, el proyecto de la Ciudad Universitaria, que por iniciativa de Costa se desarrollaba como alternativa moderna al proyecto que Marcello Piacentini había presentado el año anterior, quedó plasmado en una serie de dibujos que ponen en evidencia la influencia de Le Corbusier y algunas de sus propuestas anteriores como, por ejemplo, el Mundaneum (1929) y el Palais des Soviets (Moscú, 1931). Sin embargo, el proyecto de Costa y Le Corbusier, y otros, fueron archivados y uno distinto se erigió recién a partir de fines de los años cuarenta.

El caso de las Naciones Unidas es una muestra más de la conflictiva relación entre Le Corbusier y las Américas y constituye uno de los episodios más polémicos, controvertidos y complejos en la carrera del arquitecto y de la arquitectura del siglo veinte. Le Corbusier estaba persuadido que "el mundo" le debía el encargo de las Naciones Unidas en compensación por la injusticia que había sufrido veinte años antes con la descalificación de su proyecto para la Sociedad de las Naciones en Ginebra; en su autoproclamado rol de líder mundial de la arquitectura moderna (que muchos, pero no todos, le reconocían), consideraba que él debía estar a cargo del proyecto independientemente del prestigio y rol de iguales de los otros miembros del equipo internacional de proyectistas. El conflicto por el liderazgo del proceso no tardó en explotar y manifestarse en un enfrentamiento 
personal con Wallace Harrison, representante de los Estados Unidos designado como coordinador del equipo internacional. En un clásico ejemplo del crónico rechazo a aceptar una realidad que no se correspondía con su interpretación de la misma, Le Corbusier convirtió el proceso de diseño de las Naciones Unidas y su enfrentamiento directo con Harrison en una cruzada personal y una sobredimensionada polémica por las decisiones del proyecto y la autoría del edificio. Para ser justos, Le Corbusier no fue el único responsable del enfrentamiento; Harrison hizo todo lo posible para mantener a Le Corbusier a distancia prudencial evitando perder el control del proceso. La explosiva e irreconciliable relación entre ellos, inseparable de su histórica conflictiva relación con los Estados Unidos, contaminó el proceso de diseño y condicionó la colaboración de los miembros del equipo internacional. Frustrado por lo que él percibía como un constante rechazo a su persona y a sus ideas por parte de los Estados Unidos decidió auto-marginarse del resto del proceso y aprovechó cuanta oportunidad tuvo para fustigar las decisiones de Harrison a quien hizo responsable por su frustrada participación en el proceso y acusó de haberse apropiado de sus ideas sin reconocérselas. Efectivamente, Le Corbusier tuvo un rol importante en las etapas preliminares del proceso de diseño, pero aunque reclamó la autoría de la idea, la impronta de su participación en la versión final solo abarca aspectos formales del complejo edilicio.

En los años cincuenta y sesenta Le Corbusier recibió frecuentes contactos para encargarse de proyectos desde diversos puntos de las Américas, pero los rechazaba casi sistemáticamente; tantas frustraciones y oportunidades perdidas habían minado su confianza y su entusiasmo por el continente americano había sido reemplazado por la segura concreción de obras en India. Sin embargo, cuando un proyecto atraía su atención, no dudaba en dejar atrás amarguras y frustraciones. En 1951 aceptó un encargo sui-generis formulado por Lucie DelgadoChalbaud: un Monumento Funerario en Caracas en memoria de su esposo asesinado meses antes mientras ejercía la presidencia de Venezuela. La historia de este proyecto está rodeada de situaciones confusas, desde la decisión de Le Corbusier de hacerse cargo del mismo y la forma en la que lo desarrolló, hasta la misteriosa desaparición de casi toda la documentación gráfica del proyecto. Interpretando con excesivo optimismo información que había recibido de su cliente, Le Corbusier pensó que la concreción de este proyecto estaba garantizada, pero seguramente desconocía la compleja trama política que había detrás y las pocas posibilidades de concreción que su proyecto realísticamente tenía ya que el gobierno venezolano lo rechazó y en su lugar construyó un proyecto de Luis Malaussena.

El último proyecto para el continente americano en el que trabajó Le Corbusier fue la Embajada de Francia en Brasilia. La idea de proyectar la nueva capital de Brasil en el desértico Planalto le entusiasmaba desde los años veinte pero el concurso de anteproyectos no admitió la participación de profesionales extranjeros. Una ilusión incubada por largos años quedaba abortada rápidamente, pero restaba la posibilidad de construir obras importantes en la ciudad proyectada por sus viejos amigos Lucio Costa y Oscar Niemeyer. A ellos recurrió buscando apoyo para obtener el encargo de la Embajada de Francia aún antes que Brasilia fuera inaugurada. Además de esta, se contemplaban otros encargos - La Maison de la France y un Centro Cultural- en los que Le Corbusier demostró mayor interés que en la embajada propiamente dicha. En diciembre de 1962, aun antes de firmar el contrato, Le Corbusier visitó en Brasilia el sitio designado para la embajada. Proyectada en París en 1963, hacia mediados de 1964 Le Corbusier consideró que el proyecto estaba concluido y listo para ser ejecutado bajo la supervisión de Oscar Niemeyer. Pero un golpe de estado militar obligó a Niemeyer a emigrar y el proceso entró en un impasse. Años más tarde, luego del deceso de Le Corbusier, la Cancillería francesa pidió cambios al proyecto original pero los herederos del atelier de la rue de Sèvres rechazaron hacer cambios al proyecto de Le Corbusier y un nuevo proyecto fue encargado a Guillermo Jullian de la Fuente, colaborador de Le Corbusier en el proyecto original. El último proyecto de Le Corbusier en las Américas se sumó así, póstumamente, a la larga lista de procesos inconclusos. 


\section{Malentendidos transatlánticos: dos planes fallidos}

Si muchos de los proyectos de Le Corbusier para el continente americano estuvieron marcados por algún tipo de malentendido o desencuentro esto llegó a niveles mayúsculos con los planes urbanos que hizo para Buenos Aires y Bogotá, dos planes con historias muy disímiles pero un destino semejante. El primero de ellos fue fruto de su inagotable capacidad para producir propuestas e intentar convertirlas en algo concreto; el segundo fue el único verdadero encargo de urbanismo para una ciudad americana y es un hito del urbanismo lecorbusierano.

En una de las conferencias de 1929, Le Corbusier había formulado una propuesta de transformación de Buenos Aires que, basada en los principios de la Ville Contemporaire y el Plan Voisin, tenía como signo distintivo la creación de una Cité des Affaires sobre una plataforma en el Río de la Plata. En los años siguientes, su audaz propuesta se convirtió en una obsesión e intentó convencer a sus amigos argentinos de la necesidad de desarrollar un plan para Buenos Aires basado, precisamente, en aquellos bocetos de 1929. Pero las respuestas que él esperaba nunca llegaron y con los años dejó de insistir. Pero en 1937, la fortuita llegada de dos jóvenes arquitectos argentinos -Jorge Ferrari Hardoy y Juan Kurchan — buscando trabajo en su atelier parisino reavivó su interés. Sin encargos viables, Le Corbusier vislumbró la llegada de Ferrari Hardoy y Kurchan como una oportunidad para desarrollar un plan para Buenos Aires. Les encomendó obtener información (mapas, estadísticas, datos históricos, etc...) para llevar a cabo un ambicioso plan basado en datos sólidos y luego de varios meses de trabajo, el equipo produjo una propuesta documentada a través de una memoria descriptiva y una serie de instrumentos gráficos entre los que sobresalía un gigantesco fotomontaje de la propuesta de transformación de la ciudad superpuesta a la foto aérea de la condición existente. Hábil en el manejo propagandístico y a pesar que nadie se lo había encomendado, Le Corbusier organizó en su atelier una presentación del Plan a un grupo de invitados de la comunidad y embajada argentinas en París. Indudablemente aspiraba a obtener algún resultado concreto, pero todos sus esfuerzos, como el de sus colaboradores al regresar a Buenos Aires, fueron infructuosos. La publicación de un libro dedicado al Plan pasó a ser el objetivo principal de aquellos años, pero tampoco fue posible hasta 1947 cuando -con la oposición de Le Corbusier - Ferrari Hardoy logró publicar parcialmente el Plan en un número especial de La Arquitectura de Hoy, versión castellana de L'Architecture d'Aujourd'hui.

La decisión de Ferrari Hardoy rindió frutos: la publicación llamó la atención del Secretario de Obras Públicas de Buenos Aires y meses más tarde se creaba la Oficina del Estudio del Plan de Buenos Aires (EPBA) bajo la dirección de Ferrari Hardoy. Exultante por el logro, Ferrari Hardoy comunicó a Le Corbusier la buena noticia, pero no era el Plan que habían hecho en París sino un nuevo estudio que respondería a la nueva realidad política y social que gobernaba al país desde hacía unos pocos años. Ignorando la diferencia, Le Corbusier celebró haber logrado el objetivo y fiel a su costumbre requirió un contrato de consultor en Argentina y, "entretanto," el encargo de un edificio importante en Buenos Aires. Su pobre lectura de la situación le había generado exageradas e irrealistas expectativas de obtener encargos en Buenos Aires. Ferrari Hardoy contemplaba la participación de Le Corbusier como consultor de la EPBA, pero eso estaba sujeto a muchos factores que no controlaba y a pesar de su buena voluntad no logró obtener la contratación de Le Corbusier en Buenos Aires. Tardíamente enterado de esa situación Le Corbusier envió una carta particularmente despectiva hacia Ferrari Hardoy y Kurchan en el que manifestaba su enorme frustración con lo sucedido y daba por definitivamente cerrado el capítulo de su relación con Buenos Aires con una lapidaria declaración: "Argentina habrá hecho, en lo que a mí concierne, uno de los gestos más decepcionantes del que haya sido objeto en mi carrera." ${ }^{\prime \prime}$ El fastidio de Le Corbusier fue premonitorio ya que un mes más tarde, por razones políticas internas, la Oficina del Plan era

\footnotetext{
${ }^{6}$ Carta de Le Corbusier a Jorge Ferrari Hardoy, 10 de Octubre, 1949; Archivos FLC, T2-13 (110).
} 
desmantelada y la labor de Ferrari Hardoy y sus colaboradores pasaba a engrosar la lista de esfuerzos inútiles y oportunidades perdidas.

En New York, mientras trabajaba en el proyecto de las Naciones Unidas, Le Corbusier forjó una sólida relación con el embajador de Colombia, Eduardo Zuleta Ángel, quien con el incentivo de un posible contrato de urbanismo en Colombia lo convenció de aceptar una invitación a dar conferencias en Bogotá que eventualmente tuvieron lugar en junio de 1947. Siempre polémico y fiel a su provocador estilo, en su conferencia sobre urbanismo sorprendió a la audiencia de con una "amable declaración de guerra" al alcalde de Bogotá: criticó la expansión de la ciudad y expresó la necesidad de un enfoque más territorial, acorde con la geografía del país. ${ }^{7}$ Días más tarde el alcalde Mazuera Villegas cumplió con lo informalmente pactado con Zuleta Ángel y propuso a Le Corbusier desarrollar un plan de urbanismo para Bogotá. Para Le Corbusier, todo había salido según lo esperado, y quizás aún mejor: había sido recibido con honores, sus conferencias habían sido seguidas por una multitud, emprendía el regreso con la promesa de un encargo y, lo más importante, esa promesa provenía directamente de "la autoridad," esa figura que desde siempre le había fascinado y consideraba clave para materializar sus ideas.

Aquellos eran años de auge para la planificación urbana en Latinoamérica ya que el Banco Mundial ofrecía créditos para desarrollo urbano a ciudades que contaran con un Plan Regulador. Pero la inestabilidad política colombiana, frecuentes cambios en el Ayuntamiento y una compleja trama de intereses personales y profesionales presentaron obstáculos de todo tipo a la puesta en marcha del Plan. Uno de los problemas era la contratación directa de Le Corbusier, resistida por algunos sectores del ayuntamiento. Mazuera Villegas consideró entonces contratar a Town Planning Associates (TPA), firma consultora dirigida por Josep Lluis Sert y Paul Lester Wiener que ya trabajaba en planes para otras ciudades sudamericanas y gozaba de prestigio y reconocimiento en Bogotá, pero Sert rechazó la propuesta porque sabía que Mazuera ya se lo había ofrecido anteriormente a Le Corbusier. La situación fue eventualmente desbloqueada en marzo de 1949 con la firma de un contrato que estableció la colaboración entre Le Corbusier y TPA; paralelamente se creó en Bogotá la Oficina del Plan Regulador de Bogotá (OPRB), ente municipal encargado de preparar la información necesaria para el desarrollo del Plan y eventualmente encargarse de su implementación.

A ojos de Le Corbusier, la situación estaba re-encaminada y el desarrollo del Plan asegurado y esto redundaría en nuevos encargos de arquitectura. La realidad, no obstante, era muy distinta; el contrato había claramente delimitado su rol poniéndolo a cargo de la segunda de cuatro etapas - el desarrollo del Plan Piloto- con Sert y Wiener actuando como consultores asociados; luego, en la tercera etapa se invertían los roles: TPA estaba a cargo del Plan Regulador basado en el Plan Piloto y Le Corbusier pasaba al rol de consultor. Pero Le Corbusier tenía su propia interpretación y pensaba que por encima de aspectos contractuales lograría mantenerse involucrado en el proceso y obtener encargos importantes. Algunos episodios preanunciaron fricciones y situaciones conflictivas, pero en 1949 el proceso siguió el curso previsto y en agosto Le Corbusier, Sert, Wiener y Herbert Ritter (Director de la OPRB) se reunieron en Cap Martin para delinear las bases del plan. El proceso continuó más tarde en París donde Le Corbusier y su equipo desarrollaron el Plan Piloto guiados, como sugiriera Fernando Arias Lemos, por el piloto automático de los principios urbanísticos del CIAM. ${ }^{8}$ En franco contraste con el optimismo de Le Corbusier -que ignoraba (por ignorancia o por conveniencia) la frágil estructura de

\footnotetext{
${ }^{7}$ Conferencia de Le Corbusier "L'urbanisme comme ordonnateur social," dictada en Bogotá el 18 de Junio de 1947. Para una transcripción virtualmente completa de la misma ver: O'Byrne, Mariia Cecilia (ed.). Le Corbusier en Bogotá 19471951. Tomo 2: Precisiones en torno al plan director. Bogotá: Ediciones Uniandes, 2010 (22-33).

${ }^{8}$ Arias Lemos, Fernando. Le Corbusier en Bogotá, El proyecto del "grand immeuble" 1950-1951; Bogotá: Universidad Nacional de Colombia-Facultad de Artes, 2008 (20).
} 
apoyos en los que se sustentaba todo el proceso - en Colombia había mucha oposición al desarrollo del Plan. Además, la persistente inestabilidad política había provocado la partida de Mazuera Villegas y Herbert Ritter. El reemplazante de Ritter, Carlos Arbeláez, era adepto a las ideas de Le Corbusier pero el apoyo del nuevo alcalde, Santiago Trujillo, estaba lejos de ser incondicional.

En Septiembre de 1950 Le Corbusier presentó el Plan Piloto en Bogotá. Antes de regresar a París recibió el reconocimiento y agradecimiento del Ayuntamiento y del alcalde Trujillo. Inmutable, Le Corbusier interpretó la presentación del Plan como ampliamente exitosa, pero en realidad el Plan fue mucho más cuestionado que lo esperado. No obstante, su interpretación del contrato era que habiendo presentado el Plan Piloto se le debía inmediatamente encargar el diseño de edificios importantes, por ejemplo el Centro Cívico (parte importante de su propuesta). Su obstinación con este tema lo llevó a desoír las advertencias que Sert y Wiener, mejores intérpretes de la realidad política y social latinoamericana, le enviaban con frecuencia. Exasperado por la falta de respuestas el tono de sus cartas subió poco a poco y llegó a un punto álgido cuando fue obligado a celebrar una última reunión de trabajo en Bogotá que estaba originalmente prevista en New York. Indudablemente, el clima de colaboración profesional y mutua confianza que había reinado en Cap Martin en agosto de 1949 se había enrarecido y condicionaba la continuación del proceso. Aun así, Le Corbusier volvió a Bogotá en Mayo de 1951 para presentar la versión final del Plan Piloto. El Ayuntamiento se esforzó en difundirlo a través de una exposición y conferencias, pero las críticas y oposición al Plan continuaron ganando adeptos.

Con la entrega y presentación definitiva del Plan Piloto concluía la segunda etapa del proceso y comenzaba la tercera en la que Le Corbusier pasaba a tener el rol de consultor de Sert y Wiener, pero una vez más volvió al ataque reclamando encargos importantes, en este caso, el Palacio Presidencial. No se percataba que su insistencia solo lograba erosionar la relación con sus socios y generaba rechazos y resistencia en Colombia. Entretanto, Sert y Wiener tomaron las riendas del proceso; era obvio que circunstancias ajenas a la arquitectura y el urbanismo hacían inviable el Plan de Le Corbusier tomado como una totalidad. Sert y Wiener pronto introdujeron cambios en el Plan Piloto que pusieron de manifiesto las diferencias conceptuales entre Sert y Le Corbusier aunque, quizás para no exacerbar más a Le Corbusier, mantuvieron el Centro Cívico virtualmente intacto. Sert y Wiener continuaron su tarea según contrato a lo largo de 1952 y 1953 en condiciones francamente adversas ya que la culminación exitosa del proceso no estaba garantizada. En Agosto de 1953 hicieron la entrega final del Plan Regulador; previamente, en junio, un golpe de estado militar había interrumpido la continuidad democrática y un gobierno de corte populista y dictatorial asumió el poder del país. Una vez más, Le Corbusier entrevió que con el cambio de autoridades surgía una nueva oportunidad para obtener el encargo de "su" Centro Cívico. Trujillo había sido nombrado Ministro de Obras Públicas de Colombia y a él volvió a dirigirse reclamándole el contrato del Centro Cívico que, según él, le había sido prometido; como si nada hubiera pasado intentó restablecer la colaboración. Sin embargo, si bien el Plan había sido sancionado como normativa urbana para la capital colombiana, el poder de turno decidió que un nuevo complejo edilicio para sede del gobierno nacional debía emplazarse fuera de los límites de la ciudad definidos en el Plan Piloto y no en el Centro Cívico como lo había propuesto Le Corbusier, sellando de esta forma su sueño de darle forma a una ciudad capital. Efectivamente, en Mise au point, Le Corbusier recordaba que en Bogotá, en 1950, había sentido que "había pasado una página," pero la realidad sobrepasó sus expectativas; los malentendidos, propios y ajenos, nuevamente causaban el naufragio de uno de sus proyectos en las Américas y

\footnotetext{
9 Žaknić, Ivan. The Final Testament of Pere Corbu: a translation and interpretation of Mise au point. New Haven and London: Yale University Press, 1997 (87).
} 
así el Plan de Bogotá y con él el complejo de edificios que había imaginado para el Centro Cívico se incorporó a la larga lista de frustraciones.

\section{Dos obras concretadas}

La lista de proyectos frustrados es efectivamente larga y no hay duda que numerosos malentendidos contaminaron muchos procesos condicionando su concreción. Pero sería incorrecto afirmar que los malentendidos sean causa única de las pocas concreciones; es plausible también pensar lo opuesto: que el malentendido sea dar por sentado que todos los proyectos estaban llamados a concretarse. Por eso quizás sea más adecuado pensar en un desencuentro: dos corrientes que por mutuo interés están llamadas a converger pero que por una o múltiples razones el encuentro entre ambas no se consuma. De la larga lista de procesos interrumpidos hay dos excepciones: la Casa Curutchet y el Carpenter Center; en ambas Le Corbusier desplegó todo el arsenal de sus ideas y lenguaje arquitectónico como si quisiera dejar firmemente establecido el legado de su obra en suelo americano. Pero estas dos obras podrían haber fácilmente pasado a engrosar la lista de frustraciones si no hubiera sido por la determinación de dos paladines de la arquitectura moderna -Amancio Williams y Josep Lluis Sert-y su incondicional lealtad a Le Corbusier. Ambos condujeron los respectivos procesos de concreción con paciencia y profesionalismo, aun cuando se vieron forzados a hacer algunos ajustes en las obras que alteraron el proyecto original. Sin embargo, a pesar de estos cambios, la autenticidad corbusierana de estos dos edificios es incuestionable. Los dos casos son distintos; en el caso de la Casa Curutchet, Le Corbusier virtualmente se desentendió del proyecto una vez que lo envió a su cliente y delegó toda la responsabilidad en Amancio Williams, fiel intérprete de las ideas del que consideraba su maestro. En el caso del Carpenter Center, Le Corbusier tuvo activa participación en todas las etapas del proceso y gracias a ello se evitaron erróneas interpretaciones de su proyecto que seguramente hubieran tenido consecuencias negativas en el resultado final, pero fue gracias a la mediación permanente de Sert - a su habilidad diplomática para consensuar posiciones y a su determinación para evitar que el proceso descarrilara- que la obra fue concluida con éxito.

La Casa Curutchet es una verdadera joya arquitectónica, un ejemplo extraordinario de la arquitectura de Le Corbusier en los años que siguieron al fin de la segunda guerra mundial, período en el cual el arquitecto llevó a cabo un replanteo de sus ideas, postulados y lenguaje arquitectónicos de las dos décadas precedentes. En esta obra reaparecen con nuevo ímpetu los cinco puntos para una nueva arquitectura enunciados a mediados de los años veinte pero aggiornados y enriquecidos con elementos desarrollados en los años treinta y cuarenta como el pan-de-verre, el brise-soleil y la implementación del Modulor como sistema que gobierna las dimensiones de todos los elementos del edificio. Pero el valor arquitectónico de esta obra no está determinado por la incorporación de dichos elementos sino por la inteligencia conceptual para resolver la complejidad del programa en un terreno exiguo y la inserción del edificio en el heterogéneo contexto de la calle, y por la brillante interacción de los elementos arquitectónicos que generan una maravillosa secuencia espacial que exalta la relación de la casa con el parque que enfrenta.

Distinto por escala, magnitud y trascendencia, el Carpenter Center es también un ejemplo notable de la arquitectura de Le Corbusier, quizás la más importante de las obras construidas en los últimos años de su vida. En el Carpenter Center Le Corbusier se propuso intencionalmente hacer una "demonstración americana" de sus ideas y postulados, y del lenguaje arquitectónico que exploró y desarrolló a largo de más de cuarenta años de actividad profesional. Todos los elementos distintivos de su arquitectura están presentes, desde los emblemáticos pilotis y la consecuente planta libre, hasta los más recientes aereateurs y ondulatoires, pasando por los brise-soleil y pan-de-verre, la materialidad y expresividad del béton brut y el protagonismo de la rampa y 
su implícita promenade architecturale. Una verdadera demonstración de arquitectura corbusierana en el corazón intelectual de los Estados Unidos, un país que identificaba como hostil a sus ideas y donde, como escribiera H. R. Hitchcock, seguramente hubiera podido tener una relación más productiva si hubiera hecho esfuerzos por entender mejor su cultura, ${ }^{10}$ afirmación seguramente extensible al resto de las Américas.

En síntesis, el balance de la relación de Le Corbusier con el continente americano puede parecer magro, pero objetivamente no lo es si se considera que dicho promedio seguramente no difiere mucho de lo que arroja la totalidad de la obra de Le Corbusier y, sobre todo, si se tiene en cuenta el valor de su obra americana. Más allá de todos los malentendidos y recíprocos desencuentros, el legado americano de Le Corbusier quedó plasmado en un puñado de proyectos indudablemente interesantes -Ocampo, Delgado Chalbaud, Plan de Buenos Aires- dos hitos en el conjunto de su obra -la Casa Errázuriz y el Plan de Bogotá- y dos auténticas obras maestras, una en cada hemisferio, que son el testimonio vivo y concreto de su recherche patiente y de la fibra poética de su arquitectura.

${ }^{10}$ Hitchcock, Henry Russell. “Le Corbusier in the United States.” Zodiac \#16 (16) 


\section{Imágenes}

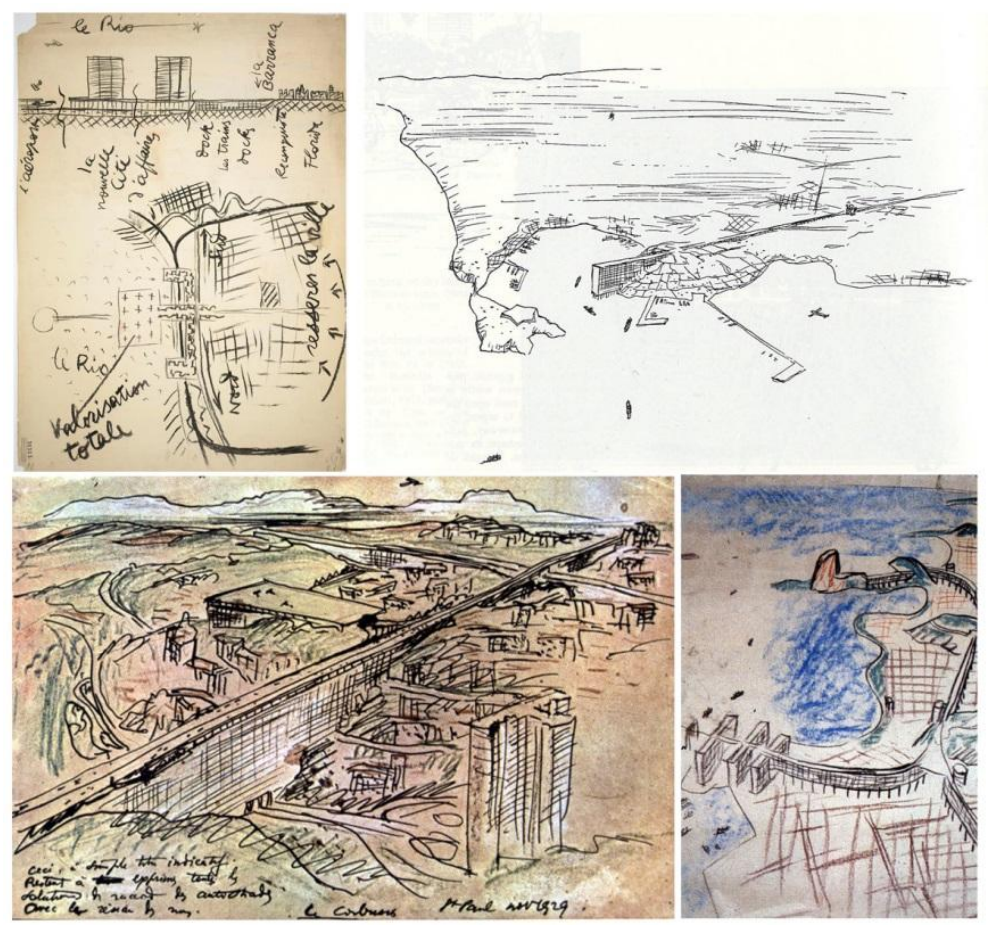

1. Bocetos de propuestas urbanas para Buenos Aires, Montevideo, São Paulo y Río de Janeiro producidas durante sus conferencias de 1929.

[Fuente: FLC Archives @FLC-ADAGP]
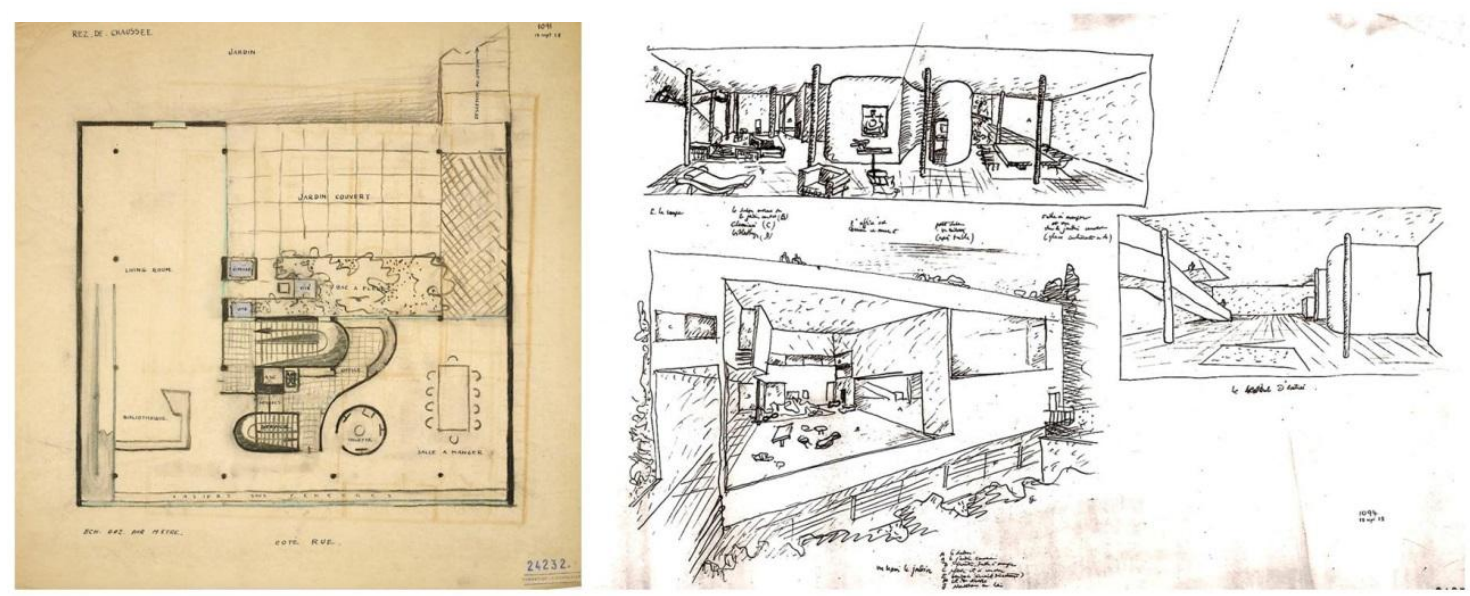

2. Villa Ocampo, Buenos Aires, Argentina; proyecto, 1928; planta del piso principal y perspectivas interiores y exterior. [Fuente: FLC Archives OFLC-ADAGP]
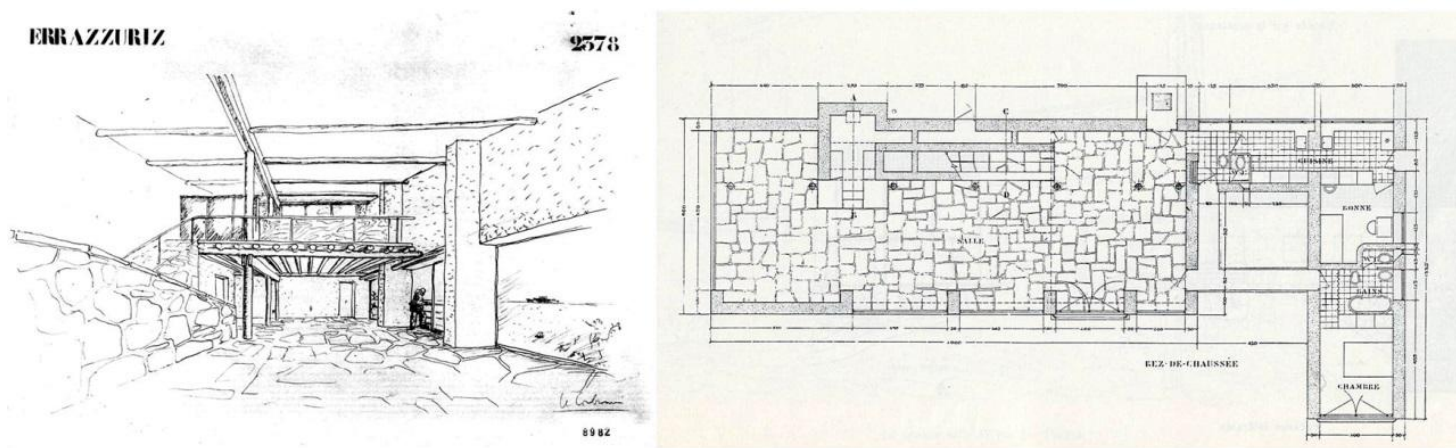

3. Casa Errázuriz, Zapallar, Chile; proyecto, 1930; perspectiva interior y planta principal.

[Fuente: FLC Archives OFLC-ADAGP] 


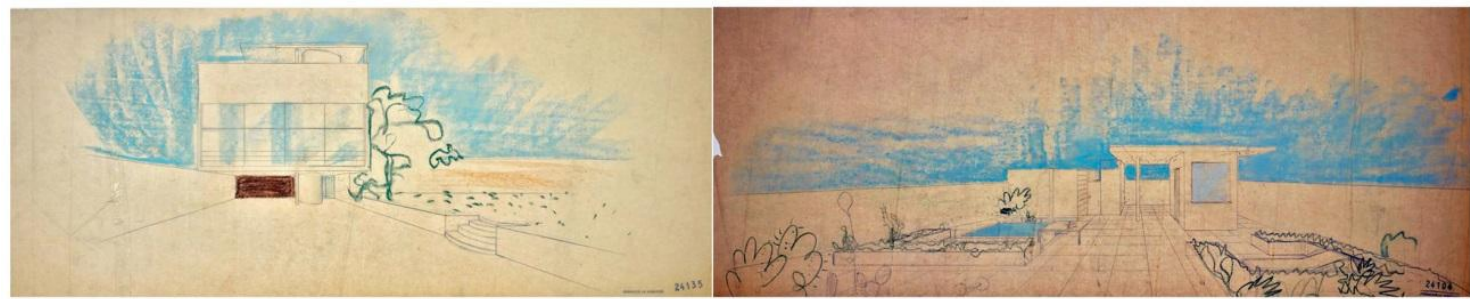

4. Villa Martínez, Buenos Aires, Argentina; proyecto, 1930; perspectiva exterior y de la terraza jardín. [Fuente: FLC Archives OFLC-ADAGP]
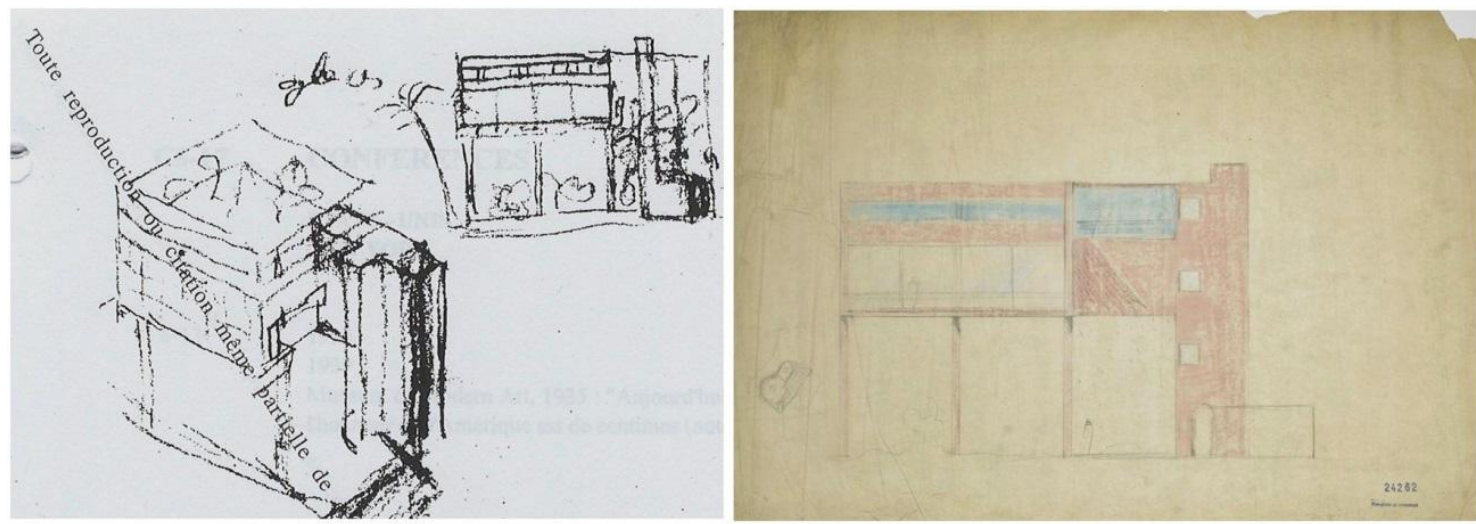

5. Biblioteca para Paulo Prado, São Paulo, Brasil; proyecto, 1930; estudios esquemáticos y fachada principal. [Fuente: FLC Archives $\odot$ FLC-ADAGP]
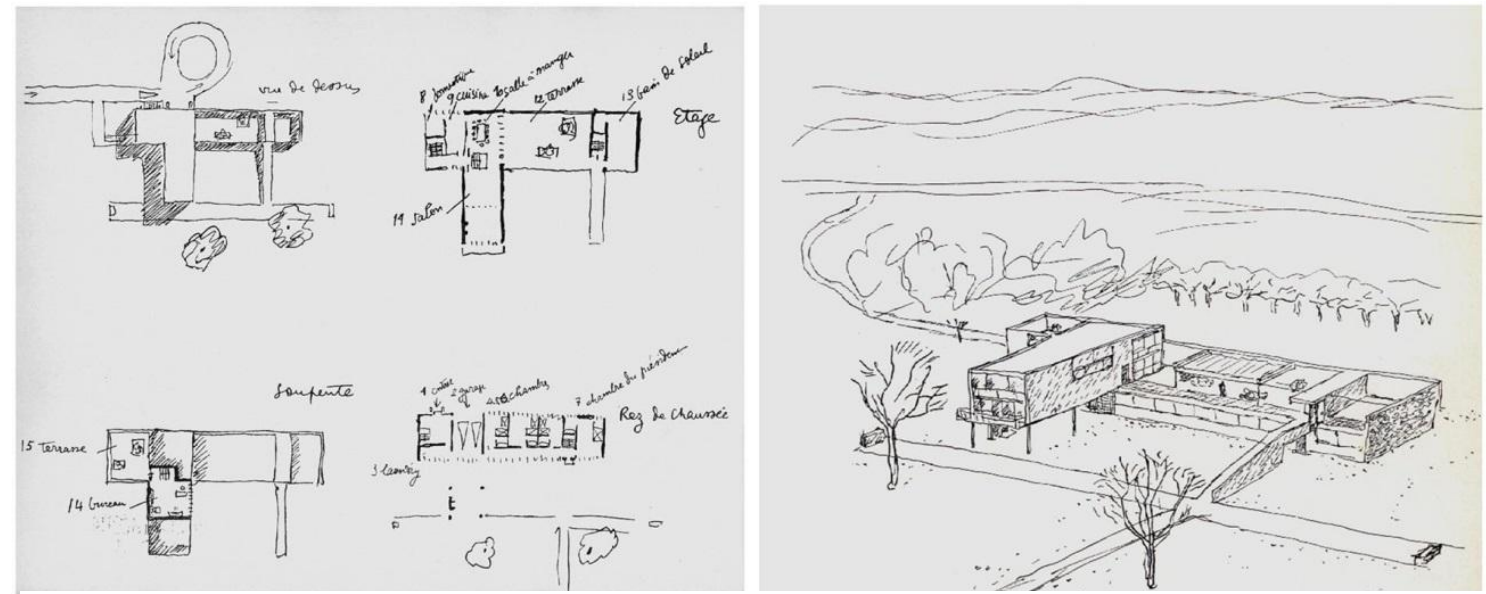

6. Casa para el Presidente del Olivet College, Michigan, Estados Unidos; proyecto, 1935; plantas y axonometría. [Fuente: FLC Archives OFLC-ADAGP]
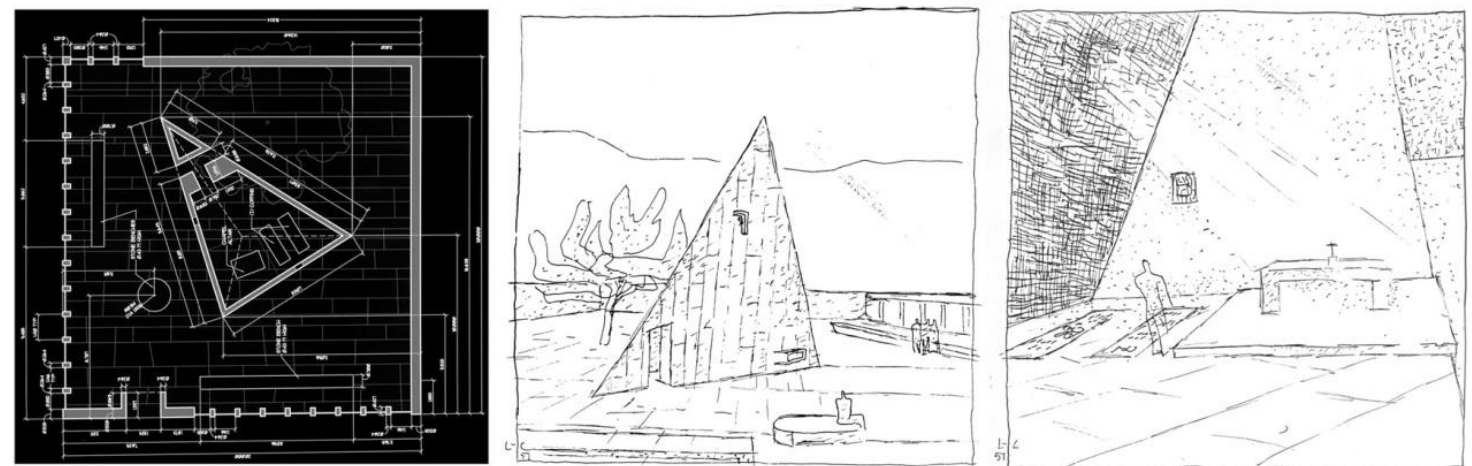

7. Monumento Funerario Delgado-Chalbaud, Caracas, Venezuela; proyecto, 1951; planta [reconstrucción], y perspectivas exterior e interior [Fuente de las dos imágenes de la derecha: FLC Archives @FLC-ADAGP] 

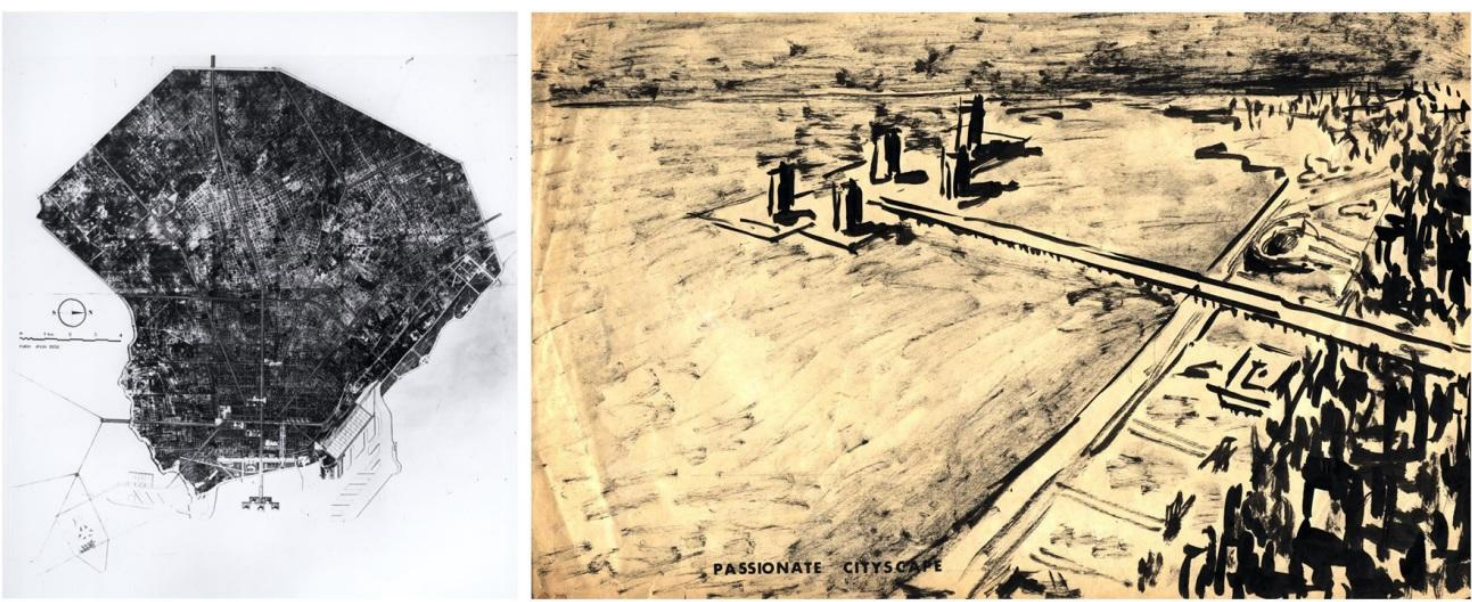

8. Plan Regulador de Buenos Aires, Argentina, propuesta, 1938; fotomontaje de la propuesta sobre la fotografía aérea de la ciudad y perspectiva de la Ciudad de Negocios (Cité des Affaires) sobre el Río de la Plata.

[Fuente: cortesía de la Francis Loeb Library, Harvard University Graduate School of Design OFLC-ADAGP]

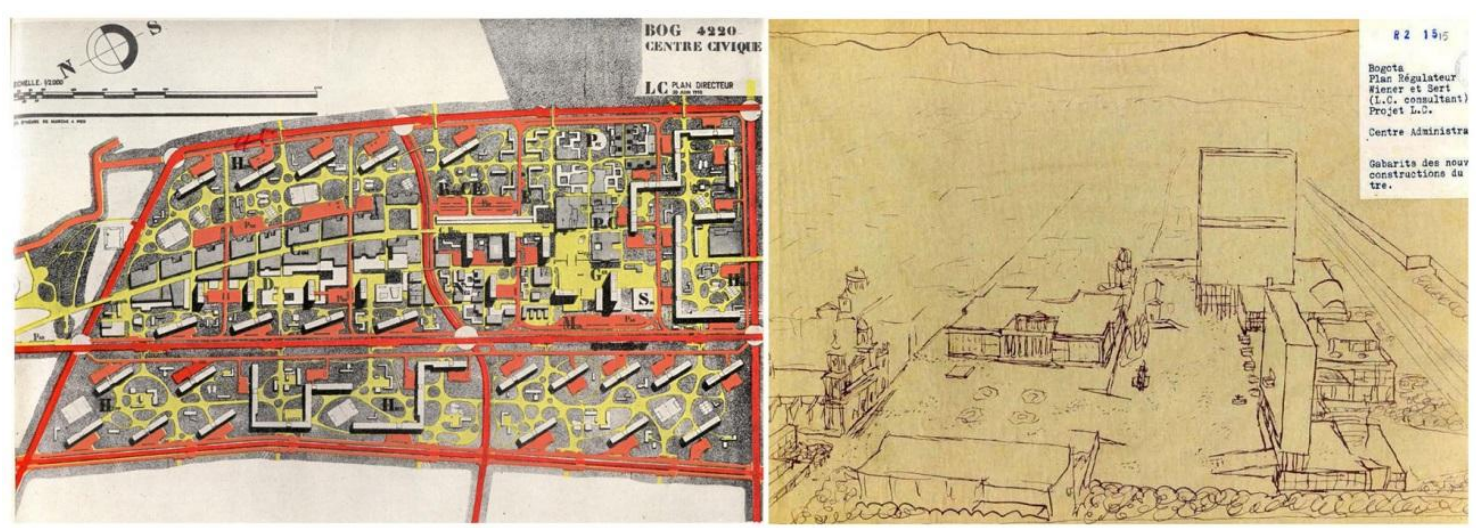

9. Plan de Bogotá, Colombia, 1951-1952, plano de detalle y perspectiva esquemática del Centro Cívico. [Fuente: FLC Archives CFLC-ADAGP]

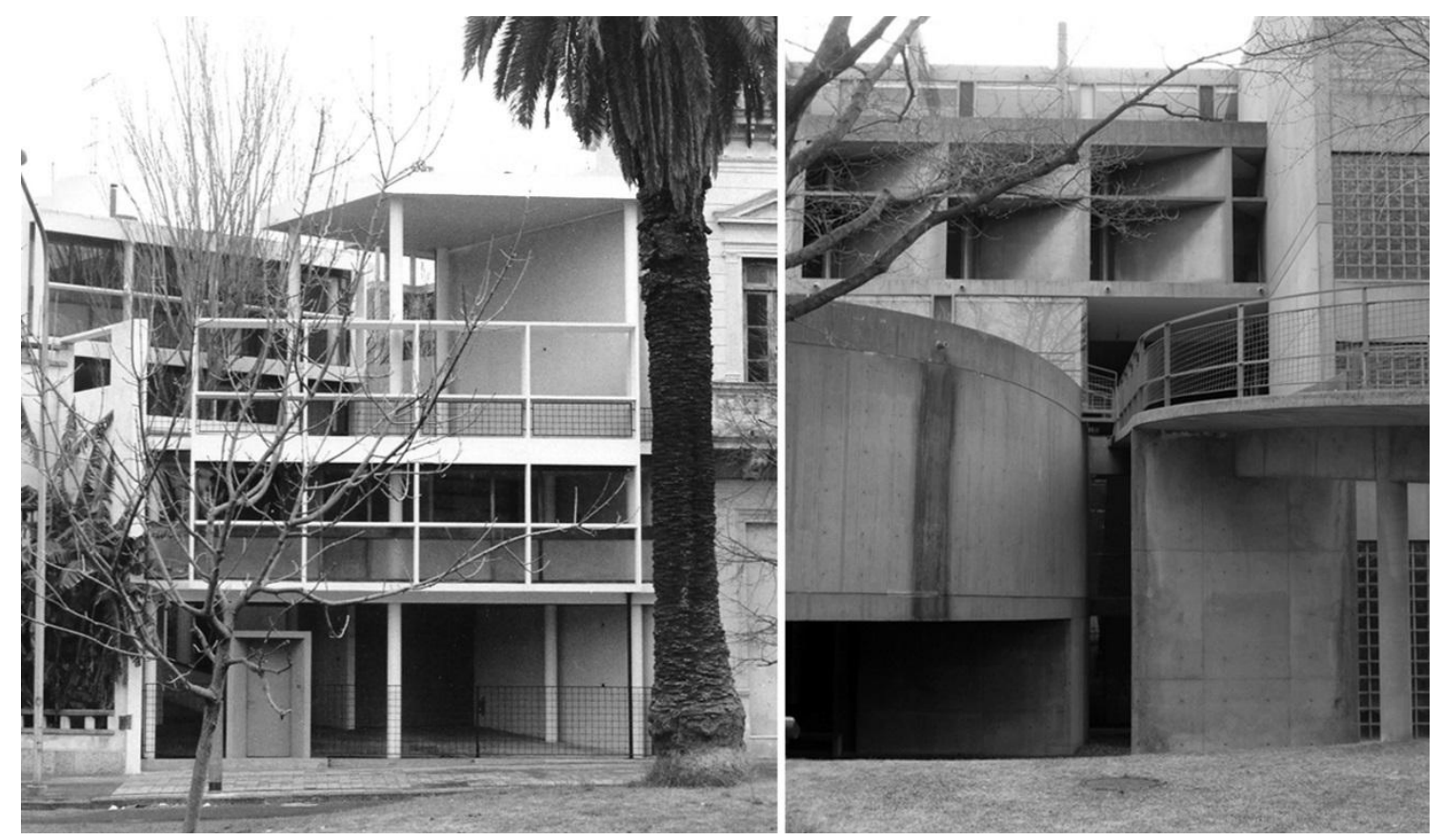

10. Casa Curutchet, La Plata, Argentina, 1949-1954; vista exterior del frente sobre Calle $\mathrm{N}^{\circ} 53 /$

Carpenter Center for the Visual Arts, Cambridge, Massachusetts, 1960-1963; fragmento de la fachada sobre Prescott Street. [Fuente: colección personal del autor] 


\section{Bibliografía/referencias}

Arias Lemos, Fernando, Le Corbusier en Bogotá: el proyecto del "grand immeuble," 1950-1951; Bogotá: Universidad Nacional de Colombia-Facultad de Artes, 2008.

Bacon, Mardges, Le Corbusier in America. Travels in the Land of the Timid; Cambridge (MA) -London: The MIT Press, 2001.

Curtis, William J. R. Le Corbusier Ideas and Forms; New York: Rizzoli, 1987

Dudley, George A. A workshop for peace: designing the United Nations headquarters, New York: Architectural History Foundation, 1994.

Hernández Rodriguez, Carlos Eduardo. Las ideas modernas del Plan para Bogotá en 1950; Bogotá: Alcaldía Mayor de Bogotá, 2004.

Lapunzina, Alejandro, Le Corbusier's Maison Curutchet; New York: Princeton Architectural Press, 1997.

Liernur, Jorge F.; Pschepieurca, Pablo. La Red Austral. Obras y proyectos de Le Corbusier y sus discípulos en la Argentina (1924-1965); Bernal (Argentina)-Buenos Aires: Universidad de Quilmes and Prometeo Libros, 2008.

Lissovsky, Mauricio; Moraes de Sá, Paulo Sergio. Colunas da Educação: a construção do Ministérioo da Educação e Saúde; Río de Janeiro: NINC/IPHAN-Fundação Getúlio Vargas, 1996.

Mostafavi, Mohsen (ed.) Le Corbusier and the Architecture of Reinvention; London: Architectural Association, 2003

O’Byrne, María Cecilia (ed.). Le Corbusier en Bogotá 1947-1951. Tomo 1. Elaboracion del Plan Regulador de Bogotál Tomo 2: Precisiones en torno al plan director; Bogotá: Ediciones Uniandes, 2010.

Pérez Oyarzun, Fernando (ed.). Le Corbusier y Sudamérica: Viajes y Proyectos; Santiago de Chile: Ediciones ARQ, 1991.

Rodrigues dos Santos, Cecília; Campos da Silva Pereira, Margareth; Veriano da Silva Pereira, Romão; Caldeira da Silva, Vasco; Le Corbusier e o Brasil; São Paulo: Tessela \& Projeto Editora, 1987.

Sekler, Eduard F.; Curtis, William J. R., Le Corbusier at Work. The Genesis of the Carpenter Center for the Visual Arts. Cambridge (MA)-London: Harvard University Press, 1978.

Žaknić, Ivan. The Final Testament of Pere Corbu: a translation and interpretation of Mise au point. New Haven and London: Yale University Press, 1997 (87). 